\title{
Comparison of Climate and Environment Change of the Last Interglacial Period and Holocene in Beijing Area, China
}

\author{
Yonggang Ge' ${ }^{1}$, Mingjian Wei ${ }^{2}$ \\ ${ }^{1}$ Key Laboratory of Mountain Hazards and Earth Surface Processes/Institute of Mountain Hazards and \\ Environment, Chinese Academy of Sciences, Chengdu, China \\ ${ }^{2}$ College of Resources, Environment and Tourism, Capital Normal University, Beijing, China \\ Email:gyg@imde.ac.cn
}

Received 23 April 2014; revised 21 May 2014; accepted 15 June 2014

Copyright (C) 2014 by authors and Scientific Research Publishing Inc. This work is licensed under the Creative Commons Attribution International License (CC BY). http://creativecommons.org/licenses/by/4.0/

(c) $\stackrel{\text { (i) }}{\mathrm{EY}}$ Open Access

\section{Abstract}

Research on climate changes between the last interglacial period and Holocene renders a speculation on the tendency of present climate. Fully understanding the nature of the changes will play a significant role in a better understanding of global climate change. This work discussed the climate change of the last interglacial period and Holocene in Beijing area to discover the mechanism of local palaeo-climate change. The palaeo-vegetation of the last interglacial period in Xishan Mountain of Beijing was reconstructed by pollen analysis and thermo-luminescence dating to represent the change of palaeo-climate and palaeo-environment. Palaeo-vegetation indicators demonstrated that the climate change of the last interglacial period included 6 stages and was homologous to that reflected by the records from deep sea depositions and polar ice cores, respectively corresponding to Marine Isotope Stage (MIS) 5e, 5d, 5c, 5b, 5a and the interim from MIS5 to MIS4 from the early to the late. Millennial climate abrupt events occurred in MIS 5e, which had an agreement with the records of GRIP. In addition, a climate warming event appeared in the interim from MIS5 to MIS4 and it also was found in other regions of the world. Compared with the vegetation and environment indicators of Holocene in Beijing area, it was found that the vegetation, climate and environment of the last glacial period were better than those of Holocene. The climate abrupt events not only appeared in the last interglacial period and MIS 5e, but also occurred in Holocene, whose mechanism and pattern were analogical. After analyzing the records of millennial climate abrupt change events from this work, Ice Cores and others, it was concluded that climate was instability in the interglacial period.

\section{Keywords}

Vegetation, Climate, Environment, Last Interglacial Period, MIS5, Holocene 


\section{Introduction}

It contributes to discovering the mechanism of climate change and to predict its tendency in the future that studies the nature of palaeo-climate of the last interglacial period and Holocene. The last interglacial period was proved to consist of 5 climate stages according to the records of deep sea depositions [1] and polar ice cores [2]-[4], including 3 warm stages and 2 cold stages which were homologous to MIS 5e, 5c and 5a, and 5d and 5b, respectively. This feature was confirmed generally by global records. Furthermore, the records from Greenland Ice Core (GRIP) indicated that MIS 5e also comprised 3 sub-warm stages and 2 sub-cold stages, named 5e5, 5e3 and 5e1, and 5e4 and 5e2, respectively. However, there are different opinions to MIS 5e among scientists because climatic instability has not been favored in consensus by the global records [4]-[13]. For Holocene, it is believed generally that it could be divided into 3 climatic stages, including the early (10 - 8 Ka B.P.), the megathermal stage ( 8 - 3 Ka B.P. or later) and the late. The climate has the feature of being warm and humid in the megathermal stage, whose temperature was $2^{\circ} \mathrm{C}-3^{\circ} \mathrm{C}$ higher than that of the present. Moreover, researchers found that the climate instability was a characteristic of Holocene with millennial, centennial and decennary climate abrupt events [14]-[20]. Fully understanding the mechanism of climate instability of the last interglacial period and Holocene will redound to learn climate change of the present and to be against global climate change. This paper reconstructs the palaeo-vegetation and palaeo-environment of the last interglacial period in Xishan Mountain, Beijing, which is located in the eastern edge of loess and the transition zone between continental climate and oceanicclimate, and then discussed the climate change and environment change of the last interglacial period and Holocene in Beijing area by comparing their environmental and climatic records, contributing to discovering the mechanism of climate and environment change of extratropical regions.

\section{Study Area}

Beijing with an area of $16.8 \times 10^{3} \mathrm{Km}^{2}\left(39^{\circ} 26^{\prime}-41^{\circ} 03^{\prime} \mathrm{N}, 115^{\circ} 25^{\prime}-117^{\circ} 30^{\prime} \mathrm{E}\right)$, is located in the east corner of China and the intersection of China North Plain (Huabei Plain), Taihang Mountains and Yanshan Mountains (Figure 1). Semi-humid monsoon climate with the featured of warm temperate zone dominates the region due to the impacts of west wind zone, especially Mongolia high pressure in winter. The annual mean temperature and annual mean precipitation is $11.8^{\circ} \mathrm{C}$ and $630 \mathrm{~mm}$, respectively, and $90 \%$ rainfall occurs in rain season (April to September). Deciduous broad leaf forest with grassland is the dominant vegetation, consisting of Larix, Pinus, Populus, Betula, Carpinus, Quercus, Ulmus, Acer, Tilia and dominant herbage includes Artemisia, Saussurea, Primula. The vertical difference of climate and environment results in the diversity of vegetation distribution in mountainous areas. Meadow and shrub develops in sub-alpine areas, deciduous broad leaf forest and warm temperate conifer forest or conifer and broad leaf mixed forest grow in the middle of mountains, deciduous broad leaf shrub or brushwood exist in the low of mountains, and warm temperate grassland occupies loess mesa areas.

Zhaitang basin with an average altitude of $500 \mathrm{~m}$, the site of sampling, is situated at the middle reach of Qingshui River, a tributary of Yongding River, in Xishan Mountain. The climate has the feature of temperate and semi-drought, whose annual mean temperature and annual mean precipitation is $6^{\circ} \mathrm{C}-10^{\circ} \mathrm{C}$ and $500 \mathrm{~mm}$, respectively. By virtue of perennial human activities, forest has disappeared in the basin and shrub and brushwood occupy mountain slopes. The sampling site is lied in East Zhaitang village of Zhaitang Basin $\left(39^{\circ} 58^{\prime} \mathrm{N}\right.$, $115^{\circ} 41^{\prime} \mathrm{E}$ ), the site of Malan Loess named (Figure 1). The palaeo-soil profile including $10 \mathrm{~m}$ of Malan Loess (L1), $2.8 \mathrm{~m}$ palaeo-soil (S1) and Loess (L2) from the upper to the low, which provides good environmental information and evidences for the last glacial climate circle.

\section{Methods}

\subsection{Pollen Analysis}

56 soil samples, each heavier than $600 \mathrm{~g}$, were collected by the scheme of $5 \mathrm{~cm}$ equidistant in S1 stratum to extract and analyze pollens. In the laboratory, all samples for pollen analysis were treated using the revised methodology [21]. Firstly, these samples were added Lycopodium spores as an exotic marker to determine pollen concentration, and then were treated by $\mathrm{HCl}$ (36.5\%) and $\mathrm{Na} 2 \mathrm{CO} 3$ (5\%). Subsequently, they were floated 2 times in heavy chemical liquid $\left(2.2 \mathrm{~g} / \mathrm{cm}^{3}\right)$, and then the suspensions were got by centrifugal operation and kept in specific tubes. Finally, the suspensions was disposed by $\mathrm{HF}$ and $\mathrm{H}_{2} \mathrm{O}_{2}$ to get rid of organic substance, and 


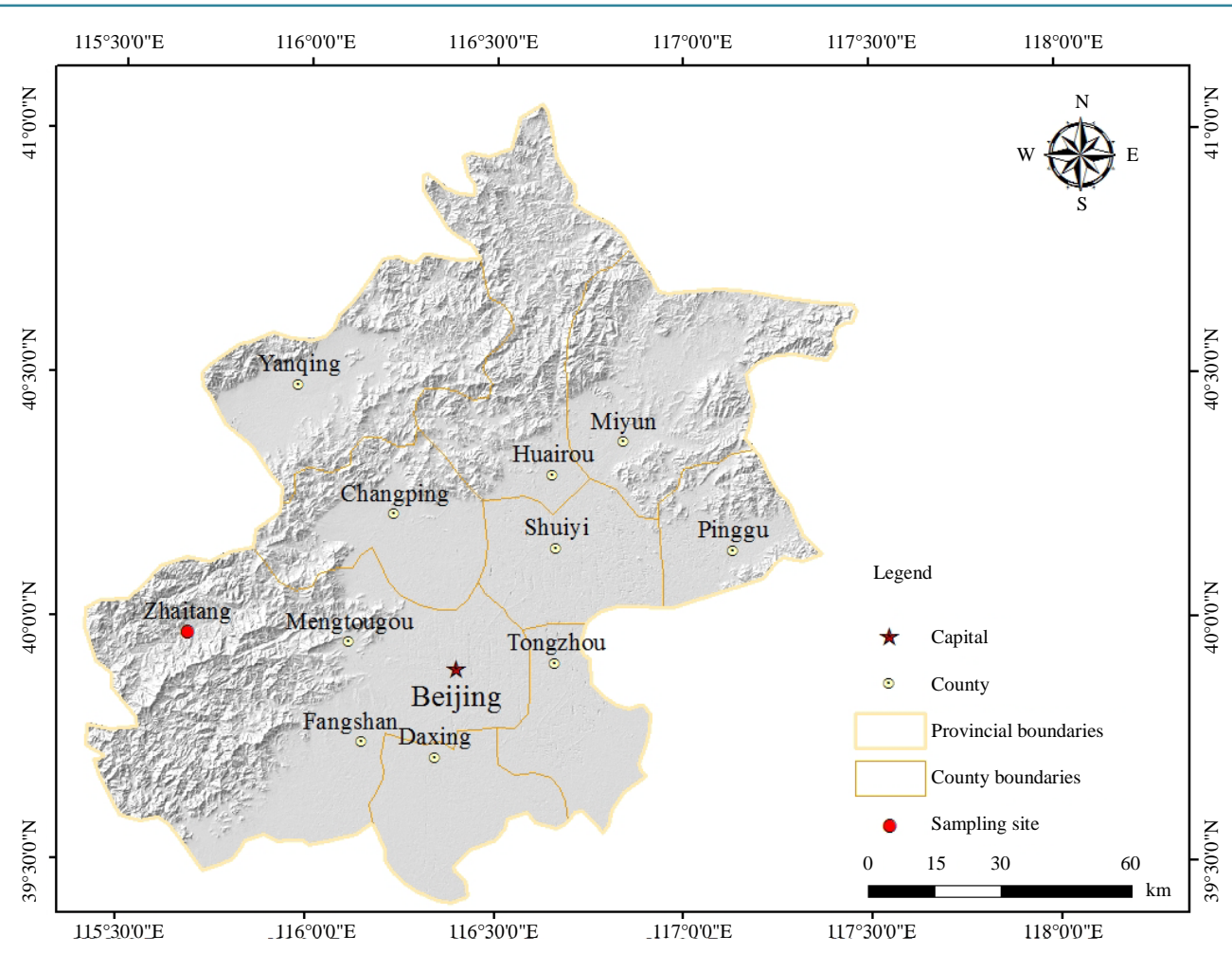

Figure 1. Location of study area.

protected by glycerin to identify the taxon of fossil pollen. Pollen identification and counts were made at $400 \times$ or 600× magnification under OLYMPUS-BX51 light microscope. Then pollen concentration and the pollen percentage of every taxon of every sample were calculated. First, confirm that you have the correct template for your paper size.

\subsection{TL Ages}

A complete S1 profile was gathered for testing TL ages, which was collected by successive aluminium tubes with un-exposed light. On the base of the results of pollen analysis, the spots of sample 1, 12, 18, 28, 39 and 56 were selected as control sites to test the ages of S1 palaeo-soil by the technology of thermo-luminescence technology. 6 samples were picked from the S1 soil profile and measured luminescence dose, calculate De and obtained ages at the Luminescence Dating Laboratory of Capital Normal University at Beijing. Under subdued red light, $20 \mathrm{~g}$ fragment of each sample was extracted to prepare fine grains for TL activity measurement. They were treated by $5 \%$ aqua fortis to remove organic materials and carbonates and to get fine quartz grains( $<74 \mathrm{um})$ [22], and then collect the 4 - 11 um fine sediment and made the discs with $1 \mathrm{~mm}$ of diameter by water-immersion to get the aliquot [23] [24].

All the TL measurements were implemented using a RGD-3B thermo-luminescence meter. A 90Sr/90Y beta source with a dose rate of $8.0 \mathrm{~Gy} / \mathrm{min}$ was used for sample irradiation to complete luminescence regenerative experiment of bleached aliquots. During the TL measurement experiment, the aliquot was heated from $20^{\circ} \mathrm{C}$ to $500^{\circ} \mathrm{C}$ with an increase rate of $5^{\circ} \mathrm{C} / \mathrm{s}$, and keep fixed temperature for $10 \mathrm{~s}$ and $30 \mathrm{~s}$ at $200^{\circ} \mathrm{C}$ and $500^{\circ} \mathrm{C}$, respectively. The photos emitting nearing 375, the peak temperature of TL, was used to estimate De value.

The single-aliquot regenerative-dose procedure provided by Murray and Wintle [25] [26] was used to recovery the process of the given laboratory dose and establish the regenerative curve to estimate the De value of each aliquot using it's natural emission photos. The error coefficient of regenerative curve of each test aliquot was kept less than 5\%, indicating over 95 percent of reliability. Then the De value of each sample was estimated by calculating the average of De values of the 5 aliquots, with less than 5 percent of standard deviation. The TL age of 6 each sample was calculated by the average value of De of 5 aliquots dividing the manual dose of natural accumulating of this sample, which was calculated by the tested content of the radioelement of $\mathrm{U}$, Th and Ka. 


\subsection{Vegetation Sequence Reconstruction}

In order to analyze the characteristics and modes of the change of palaeo-climate and palaeo-environment, the high-resolution vegetation change sequence was constructed using pollen concentration unit soil and pollen percent content of the dominant species and the TL ages of 6 control sites and the interpolating ages of other samples to reconstruct palaeo-climate and palaeo-environment. Then, the mechanism and mode of climate and environment change of the last interglacial period and Holocene in Beijing area were discussed by comparing the climatic and environmental records of these two stages.

\section{Results}

\subsection{Pollens}

Over 100 grain pollens were required to identify their species for every sample in the process of pollen analysis. The least and the most of pollen grains identified was 103 grains and 226 grains, respectively. 44 faculties and 68 genus fossil pollens were found in 56 samples in total and described as follows:

Arbor pollens-Pinus, Betula, Carpinus, Ulmus, Quercus, Tilia, Juglans, Pterocarya, Picea, Alnus, Corylus, Zelkova, Hemipteelea, Acer, Ailanthus, Castenea, Salix, Larix, Rhus, Pteroceltis, Firmiana, Keolreuteria.

Shrub pollens-Prunus, Rosa and Spiraea of Rosaceae, Elaeagnus of Elaeagnaceae and Deutzia and Hydrangea of Saxifragaceae, Sorbus, Syringa, Sedum, Rhamnus, Euonymu, Philadelphus, Chionanthus, Acacia, Ephedra.

Herbage pollens-Ranunculaceae, Polygonaceae, Cruciferae, Compositae, Artemisia, Gramineae, Chenopodiaceae, Liliaceae, Sauruaceae, Humulus, Caryophyllaceae, Umbelliferae, Cyperaceae, Amaranthaceae, Rubiaceae, Primulaceae, Leguminosae, Vitaceae, Lardizabalaceae, Papaveraceae, Cornaceeae, Ericaaeae, Bignoniaceae, Convolvulaceae, Urticaceae, Campanulaceae, Caprifoliaceae.

\subsection{TL Ages}

The tested and calculated data of 6 control samples including radioelements, De and TL were showed in the Table 1.

The TL age of sample 1, 12, 18, 28, 39 and 56 was 70.3 Ka B.P., 79.2 Ka B.P., 85.8 Ka B.P., 100.5 Ka B.P., 111.2 Ka B.P. and 129.3 Ka B.P., respectively. The TL ages of other samples were calculated by equal distance interpolation in their subsection. As a consequence, the time resolution of subsection of sample 1 - 12, 12 - 18, 18 - 28, 28 - 39 and 39 - 56 was 750 a, $1.1 \mathrm{Ka}, 1.5 \mathrm{Ka}, 1.07 \mathrm{Ka}$ and $1.06 \mathrm{Ka}$, respectively.

\subsection{Vegetation Change Sequence}

The high-resolution paleo-vegetation change sequence with the change diagram of pollen percentage and pollen concentration, was constructed based on the data of pollen analysis and TL ages. According to vegetation types reflected by fossil pollens, the palaeo-vegetation change sequence was divided into 6 zones and several subzones, which were showed as the Figure 2 (the diagram of pollen concentration and zones).

\section{Climate and Environment Change of Last Interglacial Period}

\subsection{MIS 5}

It was illuminated by the Figure 2 that the palaeo-vegetation sequence was classified into 6 pollen belts from

Table 1. De, TL ages and related data of 6 control samples.

\begin{tabular}{|c|c|c|c|c|c|c|c|}
\hline Sample No. & U (ug/g) & Th (ug/g) & Ka (ug/g) & Annual dose (mrad/a) & De (Gy) & Error (\%) & $\mathrm{TL}(\mathrm{Ka})$ \\
\hline 1 & 2.303 & 13.92 & 24,710 & 4.1619 & 292.43 & 4 & $70.3 \pm 2.8$ \\
\hline 12 & 2.291 & 12.8 & 23,760 & 3.9717 & 314.67 & 4 & $79.2 \pm 3.2$ \\
\hline 18 & 2.201 & 12.49 & 28,430 & 4.0115 & 344.26 & 4 & $85.8 \pm 3.4$ \\
\hline 28 & 2.169 & 12.71 & 23,720 & 3.9058 & 392.74 & 5 & $100.5 \pm 5.0$ \\
\hline 39 & 2.230 & 12.25 & 25,650 & 3.8785 & 431.27 & 5 & $111.2 \pm 5.6$ \\
\hline 56 & 2.143 & 12.50 & 26,580 & 4.0297 & 521.23 & 5 & $129.3 \pm 6.4$ \\
\hline
\end{tabular}




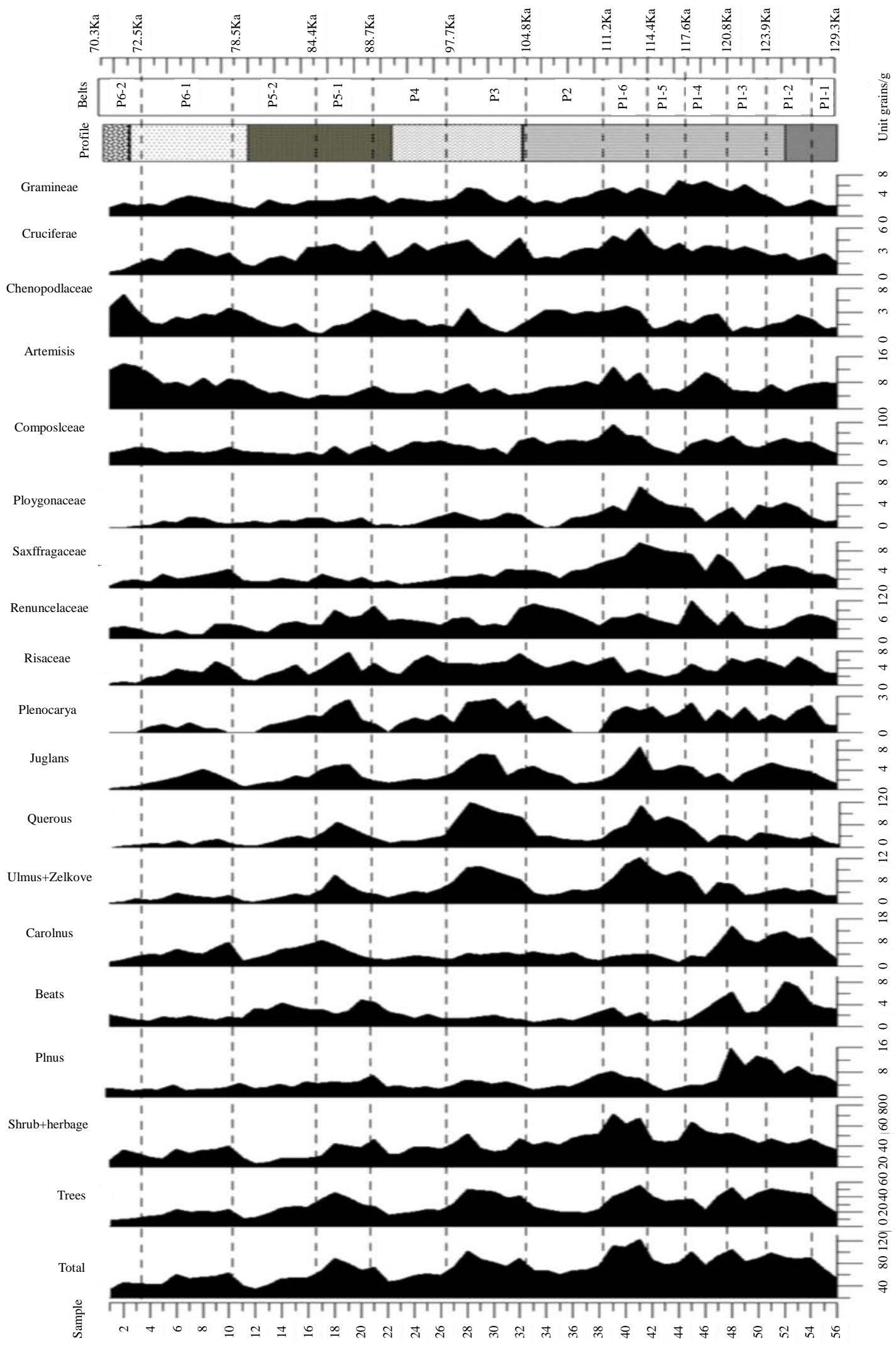

Figure 2. Pollen concentration change sequence and zones of last interglacial period at Beijing area. 
the low to the upper of the profile, including P1, P2, P3, P4, P5 and P6, which indicated that vegetation change experienced 6 stages. The characteristics of every belt were as follows:

P1: Sample 56 - 39, TL age 129.3 - 111.2 Ka B.P. Pollen concentration of each sample was beyond 80 grains/g, and the highest was 123.4 grains/g of Sample 41. The pollen percentage of arbor was almost equal to that of shrub and herbage. Dominant arboreal pollens changed from Pinus, Betula, Carpinus of the early intoUlmus and Quercusof the later. In addition, hygrophilous shrub and herbage pollens appeared in these samples, which reflected these shrubbery and grass developed well in forest. Pollen data indicated that forest evolved from conifer and broad leaf mixed forest into deciduous broad leaf forest, and climate was warm and humid.

P2: Sample 38 - 33, TL age 111.2 - 104.8 Ka B.P. The dominant pollens consisted of Ranunculaceae, Compositae, Artemisia, Rosaceae, Pinus and Carpinus. Pollen concentration varied from 60 - 70 grains/g and arboreal pollen percentage universally was less $60 \%$. Arbor pollens mainly comprised Pinus, Carpinusand Betula and some Picea pollen appeared. The pollen percentage of Ranunculaceae, Compositae and Artemisia was beyond 22\%, that of Polygonaceae decreased gradually, and that of Chenopodiaceae increased and reached about $4 \%$. These indicated that forest meadow and steppe developed, and climate was warm and dry in this period.

P3: Sample 32 - 27, TL age 104.8 - 97.7 Ka B.P. The dominating pollens included Quercus, Ulmus, Rosacea and Ranunculacea. Pollen concentration was generally beyond 80 grains/g. The pollen percentage of Quercus and Ulmus exceeded $10 \%$, respectively, and that of Pterocarya was over $2 \%$. The major shrub pollens were Rosacea and Saxifragaceae and the principal herbage pollens consisted of Ranunculacea, Artemisia and Compositae. Polygonaceae percentage underwent a change process of rose, decrease and then increase. These suggested that vegetation was deciduous broad leaf forest, and climate was warm and humid with a little fluctuation between droughty and moist.

P4: Sample 26 - 21, TL age 97.7 - 88.7 Ka B.P. The major pollens comprised Ranunculaceae, Artemisia, Compositae, Rosaceae, Pinus and Carpinus. Pollen concentration varied from 50 to 65 grains/g, and the pollen percentage of arboreal pollens in each sample was less $38 \%$. The main arboreal pollens included Pinus, Carpinus, Ulmus and Betula, and they accounted for about $20 \%$ of the total pollen. Picea pollen was also found in some samples. The pollen percentage of Rosaceae was about $6 \%$, that ofRanunculaceae, Compositaeand Artemisia was over 22\%, that of Cruciferae and Gramineae was about $10 \%$, and that of Chenopodiaceae reached $5.4 \%$ in Sample 22. These proved that vegetation was forest and grassland, and climate had the feature with cool and drought.

P5: Sample 20 - 11, TL age 88.7 - 78.5 Ka B.P. The pollen concentration decreased in fluctuation, the highest and the lowest was 88.5 grains/g in sample 18 and 35.2 grains/g in Sample 12, respectively. The percentage of arbor pollens was ordinarily about $40 \%$. This belt was also divided into two sub-belts as follow:

P5-1: Sample 20 - 17, TL age 88.7 - 84.4 Ka B.P. The pollens mainly included Ulmus, Quercus, Rosacea and Ranunculacea, and the pollen concentration was about 67 grains/g. The pollen percentage of Quercus, Ulmus, Carpinus and Juglans was beyond 26\%. Shrub and grass with the dominant species of Rosaceae, Elaeagnaceae, Ranunculacea, Artemisia and Compositae grew in forest. These showed that deciduous broad leaf forest developed well, and the climate was warm with a little drought. Moreover, the pollen percentage of Pinus and Betula increased gradually, but that of Chenopodiaceae was justly in reverse, which further proved that the temperature decreased and the humidity rose in this stage.

P5-2: Sample 16 - 11, TL age 84.4 - 78.5 Ka B.P. The major pollens were Carpinus, Pinus, Betula, Rosacea, Ranunculacea and Artemisia. The pollen concentration of every sample was below 56 grains/g and the lowest was only 35.2 grains/g in Sample 12. The pollen percentage of arbor decreased continuously, but that of Artemisia, Compositae and Chenopodiacea rose distinctly. These showed that the vegetation changed from conifer and broad leaf mixed forest into forest and grassland or grassland with sparse trees, which suggested that climate evolved from the warm-drought into the cold-drought gradually.

P6: Sample 10 - 1, TL age 78.5 - 70.3 Ka B.P. The dominant pollens composed of Carpinus, Juglans, Pinus, Artemisia, Compositae and Rosacea. Pollen concentration was about 50 grains/g, the highest 63 grains/g in sample 10 and the lowest 34.2 grains/g in Sample 1. This belt was divided into two sub-belts as follow:

P6-1: Sample 10 - 4, TL age 78.5 - 72.5 Ka B.P. The primary pollens contained Carpinus, Juglans, Pinus, Artemisia, Compositae and Rosacea. The pollen concentration was over 50 grains/g. The pollen percentage of Carpinus, Juglans and Pinus was about $20 \%$ and that of Tilia increased gradully. The dominant herbage pollens were Artemisia, Compositae and Ranunculaceae, and the pollen percentage ofChenopodiacea was about 4\%. 
These showed that vegetation was forest and grassland, and climate was warm-drought.

P6-2: Sample 3 - 1, TL age 72.5 - 70.3 Ka B.P. The principal pollens consisted of Artemisia, Compositae, Pinus and Chenopodiacea. The pollen percentage of herbage was about $70 \%$, that of Artemisia was beyond $30 \%$ and that ofCompositae and Chenopodiacea was over 17\%. The major arboreal pollens were Pinus and Betula, and some Ephedra pollen was also found. These proved that dry grassland with sparse Pinus and Betula grew, and climate was cold-drought in this stage.

It was proved from the above analysis that conifer and broad leaf mixed forest or deciduous broad leaf forest developed in the periods that corresponded to the belts of P1, P3 and P5, and forest meadow or forest grassland appeared in the stages that corresponded to the belt of P2 and P4. It indicated that there were 3 warm stages with warm-humid and 2 cold stages with temperate-drought or cool-drought, which had a good agreement with the records of deep sea deposition, especially the SPECMAP. The belt P1, P2, P3, P4 and P5 corresponded to MIS $5 e, 5 d, 5 c, 5 b$ and $5 a$, respectively. Moreover, the climate and environment of MIS 5e were better than those of $5 c$ and $5 a$, that of $5 c$ was superior to that of $5 a$ and that of $5 d$ was preferable to that of $5 b$ in Xishan Mountain of Beijing. On the whole, the climate changed from the warm-humid into the temperate-drought.

It was also confirmed that a warming event occurred in the interim from MIS 5 to MIS 4 because the vegetation of belt P6-1 was better than that of belt P5-2. The vegetation components of P6-1 were similar to those of the present vegetation in Beijing area, which indicated that the analogical climate and environment appeared in the two periods. This event was also proved by physical or chemical indictors from Zhaitang Basin of Beijing [27], and was also found in other regions by the records of Greenland Ice Core (GISP2 and GRIP) [28], Vostok Ice Core from the Southern Polar [29], N. Pachyderme (s.) concentration of Vema 2381 Core from the North Atlantic [30], loess granularity of Lijiayuan profile [31] and loess median granularity of Luochuan profile [32] from Loess Plateau.

Furthermore, the vegetation change sequence demonstrated that climate transformation of earth orbit scale (10 Ka) was a rapid process and completed with a millennial abrupt event. The transformation of P1 to P2, P3 to P4, P4 to P5, and P5 to P6 all finished between the two neighboring samples. It has a good agreement with the records from Greenland Ice Core and other records.

\subsection{MIS 5e}

The P1 belt was also divided into 6 sub-belts, which implied the climate and environment of MIS 5e experienced 6 stages. P1-1 sub-belt including sample 56 and 55 reflected the characteristics of vegetation and climate of the interim from MIS 6 to MIS 5. The other 5 sub-belts indicated the features of vegetation, climate and environment of MIS 5e as follows:

P1-2: Sample 54 - 51, TL age 128.2 - 123.9 Ka B.P. The dominant pollens were Carpinus, Pinus, Betula, Rosacea and Ranunculacea. The pollen concentration was about 90 grains/g. The pollen percentage of Carpinus, Pinus and Juglans was beyond 10\%, $8 \%$ and 4.5\%, respectively. Alnus, Pterocarya and Tilia pollens also appeared. The pollen percentage of Ranunculaceae and Artemisia decreased significantly, but that of Rosacea, Saxifragaceae and Polygonaceae increased continuously. These showed that conifer and broad leaf mixed forest developed and the climate was warm and humid in this stage.

P1-3: Sample 50 - 48, TL age 123.9 - 120.8 Ka B.P. The primary pollens included Pinus, Carpinus, Betula, Rosacea and Ranunculacea. The pollen concentration was 88.9 grains/g, 82.7 grains/g and 105 grains/g, respectively. The pollen percentage of Pinus and Carpinuswas was over 11\% and 9\%, respectively, and those of Juglans and Tilia reduced gradually. Furthermore, that of Pinus, Carpinus, Betula, Saxifragaceae and Polygonaceae all had an abrupt decrease in sample 49 and then increased significantly. These demonstrated that conifer and broad leaf mixed forest developed well, and the climate fluctuated abruptly from the warm-humid to the temperate -drought and then recovered the warm-humid. The change of vegetation and plant species also indicated that the climate and environment of this stage was worse than that of P1-2.

P1-4: Sample 47 - 45, TL age 123.9 - 120.8 Ka B.P. The pollen concentration was 92.9 grains/g, 76.3 grains/g and 100.5 grains/g, respectively. The percentage of arbor pollen decreased in large and was only $28.8 \%$ in sample 46, reaching the lowest of P1 belt. That of Pinus, Betula andCarpinus gradually decreased, but that of Quercus and Ulmus rose significantly. Moreover, some Syringa pollens appeared in Sample 46, and some pollen of Acacia that grew in the tropical and sub-tropical areas now were found in Sample 45. The pollen percentage of hygrophilous Saxifragaceae and Polygonaceae went through the change process of high, low and then high, 
but that of Artemisia and Chenopodiaceae was in the reverse. These suggested that forest or forest and meadow with conifer and broad leaf mixed forest developed in the early period and deciduous broad leaf forest grew in the late period, and climate was more instable.

P1-5: Sample 44 - 42, TL age 117.6 - 114.4 Ka B.P. The dominant pollens were Ulmus, Quercus, Saxifragaceae and Ranunculacea. The pollen concentration of all samples was about 80 grains/g. The pollen percentage of Ulmus and Quercus was above 18\%, that of Juglans and Tilia was less than that of belt P1-4, and some Castenea and Alnus pollens appeared. Besides, the pollen percentage of Saxifragaceae was beyond $10 \%$, and that of Polygonaceae was higher than that of belt P1-4. These indicated that deciduous broad leaf forest with hygrophilous shrub and herbage grew, and climate was warm-humid.

P1-6: Sample 41 - 39, TL age 114.4 - 111.2 Ka B.P. The principal pollens were similar to those of P1-5 and the pollen concentration of every sample was over 100 grains/g. The major arbor pollens contained Ulmus, Quercus, Juglans and Tilia, whose concentration reached the highest of the profile in sample 41 and then decreased gradually. As for shrub and herbage pollens, the percentage of Rosaceae, Compositaeand Artemisia rose in fluctuation, but that of Saxifragaceae and Polygonaceae decreased. These showed that deciduous broad leaf forest developed well, and the climate was the most warm-humid in the last interglacial period and then dried gradually.

From the above analysis, it was demonstrated that the vegetation evolved from conifer and broad leaf mixed forest with the majority of Pinus, Betula and Carpinus into deciduous broad leaf forest with the majority of Ulmus and Quercus. It represented more biological diversity than the present vegetation, and some subtropical species developed in this period, which indicated that palaeo-climate had the feature of warm-humid. In addition, the warm-humid level of climate increased gradually in MIS 5e and the period of belt P1-6 was the most warm-humid stage in MIS 5e and MIS 5.

Plaeo-vegetation change illuminated that the plaeo-climate of MIS 5e was instable. The climate instability was homologous to the records from GRIP because that the features of climate and environment described by P1-2, P1-3, P1-4, P1-5 and P1-6 sub-belt was consistent to those of 5e5, 5e4, 5e3, 5e2, 5 e1 reflected by GRIP records, respectively. Only was the range of climate change less than that of GRID because the climate and environment of MIS 5e was always better than that of MIS 5d and MIS 5b, but the records from GRID was not.

The climate transformation was a rapid process in MIS 5e. It was testified by the transformation from P1-6 to P1-5, which the pollen concentration increased from 86.2 grains/g of sample 42 to 123.4 grains/g of Sample 41. The similar climate transformation also occurred in the processes of P1-1 to P1-2, P1-3 to P1-4 and P1-4 to P1-5, and only their change range was less than that of P1-5 to P1-6. Moreover, climate abrupt events also appeared in the stages of P1-3 and P1-4. These suggested that millennial and even centennial climate abrupt events appeared in MIS 5e, which further suggested that climate was instability.

\section{Comparison of Climate and Environment Change between MIS 5 and Holocene}

The comparison of climate change between MIS 5 and Holocene conduces to discover the climate change mechanism of interglacial period and Holocene.

The climate and environment characteristics of Holocene in Beijing area were discovered by pollen analysis and other methodologies in the past several decades. According to pollen analysis, the grassland with the majority of Compositae and Artemisia developed in the plain areas, and conifer forest with Pinus, Picea and Abies grew in mountains with an altitude of $500 \mathrm{~m}$ in the early of Holocene. Picea distribution reached the foothills, which indicated a cold event appeared in a short time. During 8 - 6 Ka B.P., conifer and broad leaf mixed forest composed by Pinus, Quercus and Betula extensively developed, and swamps appeared, which suggested that climate was warm and humid [33]. During 6 - 2 Ka B.P., deciduous broad leaf forest developed widely and climate was warm generally. Especially in 5 Ka B.P., the deciduous broad leaf forest composed by Quercus, Ulmus, Betulaand Mulberry developed broadly [33]-[36], whose woody pollens percentage was ordinarily over $50 \%$ and the highest even reached 90\% [34]. Besides, aquicolous plants grew well in lakes and swamps. These records showed that climate was more warm and humid in this stage than in the early of Holocene. However, a short-term clod event appeared in 5.6 Ka B.P. when dark conifer forest comprised byPicea and Abies developed. During 3.5 - 3.2 Ka B.P., conifer forest extensively existed in Beijing area and then climate became cool and drought. After 2.1 Ka B.P., a cold climate event lasted for several hundred years, whose average annual temperature was lower $1^{\circ} \mathrm{C}-2^{\circ} \mathrm{C}$ than that of the present. In that time, Pinus forest dominated mountain area. However, 
it disappeared and was displaced by grassland in plain areas. After that time, the climate was temperate and cool with a little drought, whose change circle became shorter [33] [35].

Pollen analysis showed that the major species of vegetation were similar in the last interglacial period and Holocene, such as Pinus, Betula, Quercus, Ulmus, Compositae and Artemisia. In addition, Carpinus, Rosaceae, Ranunculaceae, Saxifragaceae, Cruciferae and Gramineae extensively grew in the last interglacial period, but not in Holocene, which suggested climate and environment of the last interglacial period was in diversity and better than that of Holocene. The vegetation change sequence also demonstrated that forest developed in MIS 5e, 5c, 5a, the warm-humid level of climate gradually decreased, and that of 5e was the best. Furthermore, it was proved that the climatic condition of MIS 5a was equivalent to the megathermal stage of Holocene because deciduous broad leaf forest with the majority of Ulmus and Quercus developed well in the period corresponding to P5-1 and 5 Ka B.P. Meanwhile, due to the impacts of mountain environment, the climate of Zhaitang basin was more drought than that of the plains, which resulted in the less hygrophilous pollens were found in this work. From these analyses, the climate and environment of the warm stages in the last interglacial period was superior to that of the megathermal stage in Holocene, and that of the early of 5a was similar to that of the megathermal stage of Holocene, but droughty.

The data from pollens, archeology and meteorology indicated that the average annual temperature was higher $2^{\circ} \mathrm{C}-3^{\circ} \mathrm{C}$ during $5-3.4 \mathrm{Ka}$ B.P. than in the present, and the average annual precipitation was also more [34] [36]. Therefore, the average annual temperature of the early of 5 a was higher about $2^{\circ} \mathrm{C}-3^{\circ} \mathrm{C}$ than that of the present, and the precipitation was probably equal to that of the present. Researches also found that the average annual temperature of the early megathermal stage of Holocene was higher $3^{\circ} \mathrm{C}-4^{\circ} \mathrm{C}$ than that of the present [36]. So, it was estimated that the average annual temperature of $5 \mathrm{c}$ and $5 \mathrm{e}$ was higher $3^{\circ} \mathrm{C}-5^{\circ} \mathrm{C}$ than that of the present, and the precipitation was also more.

The vegetation components of 5d, 5b and the interim from MIS 5 to MIS 4 were better than those of the early and the late of Holocene (cold stages), which implied that the climate and environment of the three stages were superior to those of the early and the late of Holocene.

The megathermal stage of Holocene and the last interglacial period, MIS 5e, had the homologous climate change mode. The pollen data showed that the megathermal stage of Holocene appeared two cold events with several hundred years, and it included 3 warm stages and 2 cold stages. This climate change mode was consistent to that of MIS 5e demonstrated by this work. The cold stage lasted less time than the warm stages in Holocene, but it was equal to or less than the warm stage in MIS 5e. Moreover, researchers found that the early of the megathermal stage was most warm-humid of Holocene, but 5e1, the late of MIS5e, was the most warm-humid period. When the time scale of climate change was unconcerned, the climate change mode of MIS 5 with 3 warm stages and 2 cold stages, were also analogical to those of the megathermal stage of Holocene. Their temperature and humidity gradually decreased, and 2 cold stages disturbed the process of climate change. It was said that the similar mechanism and mode of climate change dominated the megathermal stage of Holocene and the last interglacial period in Beijing, and climate instability was the feature of the two periods.

This study discovered that the climate of the last interglacial period and Holocene was instable. Comparing this result with the records from Ice Core and other studies, it was further proved that millennial climate abrupt events occurred persistently since 1 Ma B.P. and even the earlier [37]-[40]. Therefore, it was deduced that the climate instability maybe was a general law in interglacial periods.

It was confirmed by the above analysis that the vegetation, climate and environment of the last interglacial period was better than those of Holocene, the similar mechanism and mode of climate change dominated the megathermal stages of Holocene and the last interglacial period, and the climate of interglacial periods was in instability.

\section{Conclusion}

It was concluded from this work that the vegetation evolvement of the last interglacial period experienced six stages (P1, P2, P3, P4, P5 and P6) in Beijing area, and climate change had an agreement with that of deep sea depositions (SPECMAP) and polar ice cores, which corresponded to MIS 5e, 5d, 5c, 5b, 5a and the interim from MIS5 to MIS4, respectively. A climate warming event occurred in the interim from MIS5 to MIS 4, which was also testified in the records from Greenland Ice Core, Deep Sea Deposition and the loess. The climate of MIS 5e experienced 5 stages, which corresponded to 5e5, 5e4, 5e3, 5e2, 5e1 of the record of GRIP, respectively, and became warmer and humid with rapid fluctuation changes. $5 \mathrm{e} 1$ was the period with the best condition of tem- 
perature and precipitation in MIS 5e. Additionally, millennial climate abrupt change events occurred not only in MIS 5, but also in MIS 5e. Compared to vegetation and environment indicators of Holocene in Beijing area, it was found that the vegetation, climate and environment of the last glacial period were superior to those of Holocene. The climate abrupt events in the last interglacial period and MIS 5e also appeared in Holocene, and they were controlled by the analogical mechanism and mode. After analyzing the records of millennial climate abrupt change events from this work, Ice Cores and others, it was deduced that climate was instability in interglacial periods.

\section{Acknowledgements}

This study was jointly supported by a Natural Science Foundation Program of Beijing City (No. 8002006) and a Key Program of Technical Development Foundation of Beijing Municipal Education Commission (No. KC200810028015). The authors are grateful to the academic, technical and financial helps from Prof. LI Huhou and Dr. YU Tao.

\section{References}

[1] Imbrie, J., Hays, J.D., Martinson, D.G., et al. (1984) The Orbital Theory of Pleistocene Climate: Support from a Revised Chronology of the Marine $\delta 18$ O Record. In: Berger, A.L., Imbrie, J., Hays, J., et al., Eds., Milankovitch and Climate (Part 1), D. Reidel Publishing Company, Dordrecht, Netherlands, 269-305.

[2] Lorius, C., Jouzel, J., Ritz, C., Merlivat, L., et al. (1985) A 150,000-Year Climatic Record from Antarctic Ice. Nature, 316, 591-596. http://dx.doi.org/10.1038/316591a0

[3] Greenland Ice Core Project Members (1993) Climate Instability during the Last Interglacial Period Recorded in the GRIP Ice Core. Nature, 364, 203-207. http://dx.doi.org/10.1038/364203a0

[4] Wang, Y.Q. and Yao, T.D. (2002) Progresses in the Studies of Abrupt Climatic Change Events Recorded in Ice Cores during the Last Glacial-Interglacial Cycle. Journal of Glaciology and Geocryology, 24, 550-558.

[5] North Greenland Ice Core Project Members (2004) High-Resolution Record of Northern Hemisphere Climate Extending into the Last Interglacial Period. Nature, 431, 147-151. http://dx.doi.org/10.1038/nature02805

[6] Heusser, L. and Oppo, D. (2003) Millennial- and Orbital-Scale Climate Variability in Southeastern United States and in the Subtropical Atlantic during Marine Isotope Stage 5: Evidence from Pollen and Isotope from ODP Site 1059. Earth and Planetary Science Letters, 214, 483-490. http://dx.doi.org/10.1016/S0012-821X(03)00389-3

[7] Klotz, S., Guiot, J. and Mosbrugger, V. (2003) Continental European Eemian and Early Würmian Climate Evolution: Comparing Signals Using Different Quantitative Reconstruction Approaches Based on Pollen. Global and Planetary Change, 36, 277-294. http://dx.doi.org/10.1016/S0921-8181(02)00222-9

[8] Tzedakis, P.C., Frogley, M.R. and Heaton, T.H.E. (2003) Last Interglacial Conditions in Southern Europe: Evidence from Ioannina, Northwest Greece. Global and Planetary Change, 36, 157-170. http://dx.doi.org/10.1016/S0921-8181(02)00182-0

[9] Capers, G., Merkt, J. and Müller, H. (2002) The Eemian Interglaciation in Northwestern Germany. Quaternary Research, 58, 49-52. http://dx.doi.org/10.1006/qres.2002.2341

[10] Rousseau, D.D. and Puisségur, J.J. (1999) Climatic Interpretation of Terrestrial Malacofaunas of the Last Interglacial in Southeastern France. Palaeogeography, Palaeoclimatology, Palaeoecology, 151, 321-336. http://dx.doi.org/10.1016/S0031-0182(99)00021-8

[11] Solveig, M.S. and Knudsen, K.L. (1997) Eemian Climatic and Hydrographical Instability on a Marine Shelf in Northern Denmark. Quaternary Research, 47, 218-234. http://dx.doi.org/10.1006/qres.1996.1868

[12] Keigwin, L.D., Curry, W.B., Lehman, S.J. and Johnsen, S. (1994) The Role of the Deep Ocean in North Atlantic Climate Change between 70 and 130 kyr Ago. Nature, 371, 323-325. http://dx.doi.org/10.1038/371323a0

[13] Thouveny, N., Beanlien, J.L.D., Bonifay, E., et al. (1994) Climate Variations in Europe over the Past 140 kyr Deduced from Rock Magnetism. Nature, 371, 503-506. http://dx.doi.org/10.1038/371503a0

[14] Ge, Q.S., Fang, X.Q. and Zheng, J.Y. (2002) Study on the Characteristics of Millennial Warm and Cold Change of Climate. Progress in Natural Science, 12, 1280-1284.

[15] deMenocal, P., Ortiz, J., Guilderson, T. and Sarnthein, M. (2000) Coherent High and Low-Latitude Climate Variability during the Holocene Warm Period. Science, 288, 2198-2202. http://dx.doi.org/10.1126/science.288.5474.2198

[16] Yu, Z. and Ito, E. (1999) Possible Solar Forcing of Century-Scale Drought Frequency in the Northern Great Plains. Geology, 27, 263-266. 
[17] Wei, M.J. and Li, H.H. (1998) Millennial Global Change Records in Dark Loessial Soil of Holoence. Scientist Press International Inc., Hong Kong, 31-55.

[18] Bond, G.C., Shower, S.W., Cheseby, M., et al. (1997) A Pervasive Millennial Scale Cycle in North Atlantic Holocene and Glacial Climates. Science, 278, 1257-1266. http://dx.doi.org/10.1126/science.278.5341.1257

[19] O’Brien, S.R., Mayewski, A., Meeker, L.D., et al. (1996) Complexity of Holocene Climate as Reconstructed from a Greenland Ice Core. Science, 270, 1962-1964. http://dx.doi.org/10.1126/science.270.5244.1962

[20] Stuiver, M. and Braziunas, T.F. (1989) Atmospheric ${ }^{14} \mathrm{C}$ and Century-Scale Solar Oscillations. Nature, 338, 10411083. http://dx.doi.org/10.1038/338405a0

[21] Wei, M.J., Yin, H.S. and Chen, S.E. (2001). Effective Method of Pollens in Red Beds at Tibet Plateau. Quaternary Sciences, 21, 84.

[22] Li, H.H. (1981) Isolation of Fine Grains by Dilute Aqua Regia. Ancient TL, 14, 9.

[23] Li, H.H. (1996) Two Kindsthermo-Luminescence Dosimeter. Acta Metrologica Sinica, 17, 271-274.

[24] Li, H.H. (1999) Dating of Thermo-Luminescence. Scientist Press International Inc., Hongkong, 56-69.

[25] Murray, A.S. and Wintle, A.G. (2000) Luminescence Dating of Quartz Using an Improved Single-Aliquot Regenerative-Dose Protocol. Radiation Measurements, 32, 57-73.http://dx.doi.org/10.1016/S1350-4487(99)00253-X

[26] Murray, A.S. and Wintle, A.G. (2000) Application of the Single-Aliquot Regenerative-Dose Protocol to the $375^{\circ} \mathrm{C}$ Quartz TL Signal. Radiation Measurements, 32, 579-583. http://dx.doi.org/10.1016/S1350-4487(00)00089-5

[27] Xiong, S.F., Liu, D.S. and Ding, Z.L. (1998) Study on Climate Warming Event of the Interim from the Last Interglacial Period to the Last Glacial Period in Zhaitang Loess. Chinese Science Bulletin, 43, 1873-1877.

[28] Dansgaar, D.W., Johnsen, S.J., Clausen, H.B., Dahl-Jensen, D., Gundestrup, N.S., Hammer, C.U., Hvidberg, C.S., Steffensen, J.P., Sveinbjörnsdottir, A.E., Jouzel, J. and Bond, G. (1993) Evidence for General Instability of Past Climate form a 250-kyr Ice Core Record. Nature, 364, 218-220. http://dx.doi.org/10.1038/364218a0

[29] Barnola, J.M., Raynaud, D., Korotkevich, Y.S. and Lorius, C. (1987) Vostok Ice Core Provides 160,000 Year Record of Atmospheric $\mathrm{CO}_{2}$. Nature, 329, 408-414. http://dx.doi.org/10.1038/329408a0

[30] Bond, G., Broecker, W., Johnsen, S., McManus, J., Labeyrie, L., Jouzel, J. and Bonani, G. (1993) Correlations between Climate Records from North Atlantic Sediments and Greenland Ice. Nature, 365, 143-147. http://dx.doi.org/10.1038/365143a0

[31] Ding, Z.L., Ren, J.Z. and Liu, D.S. (1996) Study on the Millennial Abrupt Changes of Monsoon and Desert System in Later Pleistocene and Its Mechanism. Science in China (Series D), 26, 385-391.

[32] Xiao, J., Porter, S.C., An, Z., Kumai, H. and Yoshikawa, S. (1995) Grain Size of Quartz as an Indicator of Winter Monsoon Strength on the Loess Plateau of Central China during the Last 130,000yr. Quaternary Research, 43, $22-29$. http://dx.doi.org/10.1006/qres.1995.1003

[33] Kong, Z.C., Du, N.Q. and Zhang, Z.B. (1982) Plants Community Evolvement and Climate Change since 10,000 Years ago in Beijing Region. Journal of Integrative Plant Biology, 24,172-181.

[34] Xu, Q.H., Wu, C. and Wang, Z.H. (1991) Study on Natural Vegetation of Hebei Province through Pollen Analysis. Geography and Tract Research, 7, 50-53.

[35] Yan, F.H., Ye, Y.Y., Mai, X.S., et al. (1981) Study on Environment and Geological Age of Two Ores in Beijing Region from Sporo-Pollen Analysis. Seismology and Geology, 3, 51-64.

[36] Zhang, Z.B., Wang, D. and Ding, J.X. (1981) Environmental Changes since 13,000 Years Ago in Beijing Region. Scientia Geologica Sinica, 3, 259-268.

[37] Jian, Z.M. and Huang, W. (2003) Rapid Climate Change and High Resolution on Deep-Sea Sedimentary Records. Advance in Earth Science, 18, 673-680.

[38] Ito, M. and Hori Kawa, K. (2000) Millennial- to Decadal-Scale Fluctuation in the Paleo-Kuroshio Current Documented in the Middle Pleistocene Shelf Succession on the Boso Peninsula, Japan. Sedimentary Geology, 137, 1-8. http://dx.doi.org/10.1016/S0037-0738(00)00136-6

[39] Raymo, M.E., Ganley, K., Carter, S., Oppo, D.W. and McManus, J. (1998) Millennial-Scale Climate Instability during the Early Pleistocene Epoch. Nature, 392, 699-702. http://dx.doi.org/10.1038/33658

[40] Venz, K.A., Hodell, D.A., Stanton, C. and Warnke, D.A. (1999) A 1.0 Myr Record of Glacial North Atlanic Intermediate Water Variability from ODP Site 982 in the Northeast Atlantic. Paleoceanography, 14, 42-52. http://dx.doi.org/10.1029/1998PA900013 
Scientific Research Publishing (SCIRP) is one of the largest Open Access journal publishers. It is currently publishing more than 200 open access, online, peer-reviewed journals covering a wide range of academic disciplines. SCIRP serves the worldwide academic communities and contributes to the progress and application of science with its publication.

Other selected journals from SCIRP are listed as below. Submit your manuscript to us via either submit@scirp.org or Online Submission Portal.
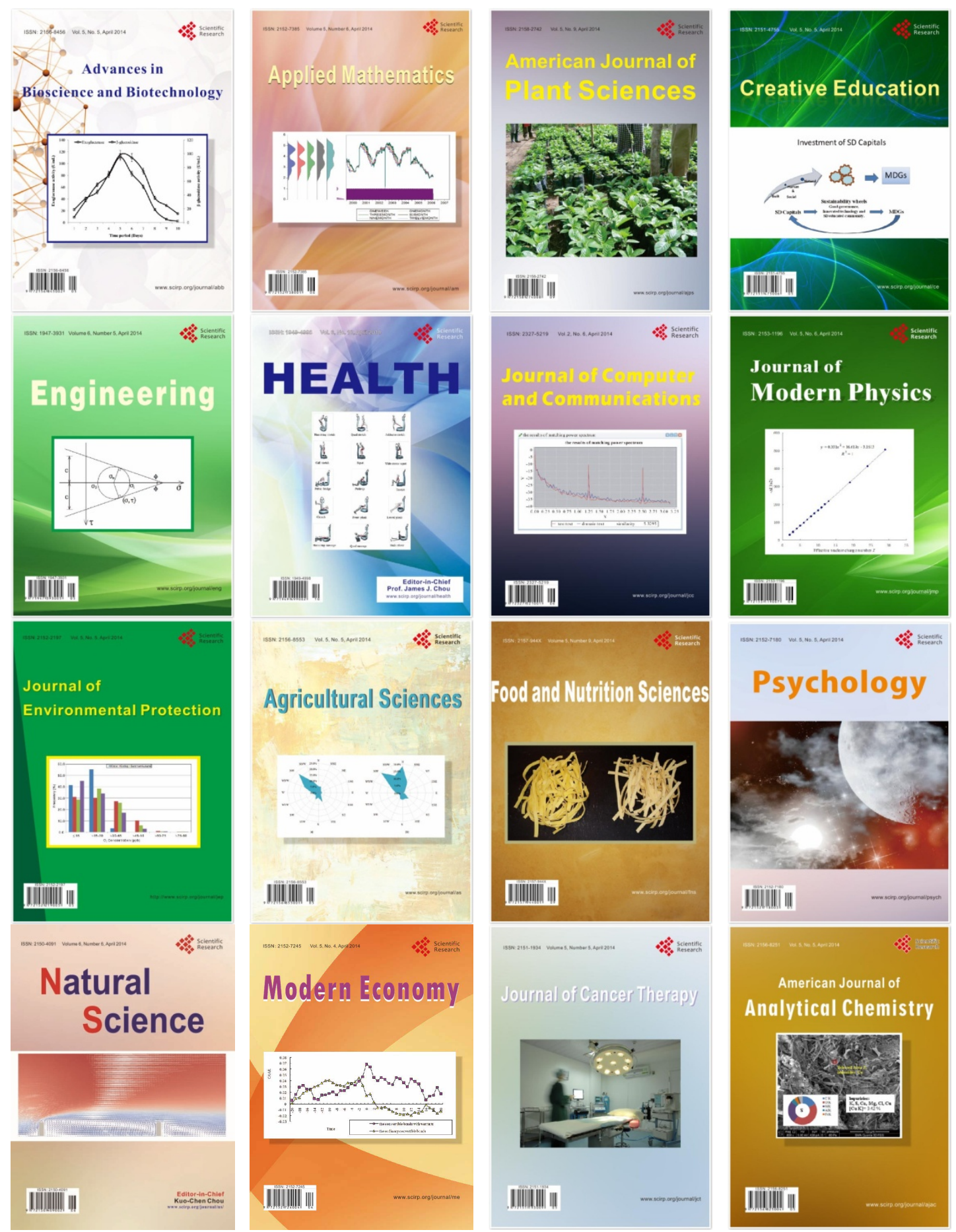